\title{
Diameter and Length Changes in Cerebral Collaterals After Middle Cerebral Artery Occlusion in the Young Rat
}

\author{
PETER COYLE \\ Department of Anatomy and Cell Biology, The University of Michigan \\ Medical School, Ann Arbor, MI 48109
}

\begin{abstract}
Rapid occlusion of the middle cerebral artery (MCA) in the 36day-old normal Wistar rat results in change of the dorsal collaterals joining branches of the anterior and middle cerebral arteries. As compared to similarly positioned vessels on the opposite hemisphere and arterioles in unoperated rats of 56 days of age, there were significantly $(P<0.001)$ more large $(60-120$ $\mu \mathrm{m})$ diameter collaterals on the occluded side 20 days after MCA occlusion. There were fewer small $(0-59 \mu \mathrm{m})$ diameter collaterals on the occluded side as compared to unoperated rats. The data suggest small diameter arterioles existing at occlusion became large diameter collaterals. The mean number of collaterals per hemisphere was not significantly different $(\mathrm{P}>0.05)$ between occluded and unoperated rats. There was no evidence that new vessels were added during the 20-day ligation period. The mean collateral tortuosity value was significantly $(\mathbf{P}<0.01)$ greater for large diameter vessels on the right occluded side as compared to vessels on the left hemisphere or vessels in unoperated age-matched control rats. The greater tortuosity values of vessels on the occluded side were evidence that collateral vessel length was increased by $24-29 \%$ after MCA occlusion. Speculation was made about possible mechanisms responsible for these vascular changes.
\end{abstract}

Unlike the adult monkey (Waltz and Sundt, 1967; Hudgins and Garcia, 1970; Garcia and Kamijyo, 1974) and the cat (Sundt and Waltz, 1966; O'Brien and Waltz, 1973; Black et al., 1979), the 5-6 week-old normal Wistar (NW) rat (Coyle, 1982) is protected against cerebral infarction following sudden occlusion of the middle cerebral artery (MCA). Since not enough time is available to increase supply by adding new vessels to avoid infarction after the rapid occlusion, adequate blood flow must occur in existing collaterals.

An earlier study (Coyle and Jokelainen, 1982) established that there were about 29 dorsal arterial collaterals for each hemisphere in 36- or 56-day-old normal Wistar rats. Because the number of collaterals did not differ significantly between the 2 age groups of NW, there was no evidence that new vessels were added during this 20-day period of life in the young rat. However, following MCA occlusion at 36 days of age, vascular change may occur during the ensuing 20-day period. The internal diameter of a vessel may enlarge, or with time, new vessels may be added to the existing vascular bed to accomodate even greater collateral supply.

The objective of this study was to determine whether or not after 20 days of MCA occlusion: 1) more collaterals were evident, 2) larger diameter collaterals were present, or 3) collateral length was increased. Comparisons were made to vessels on the side opposite to the occlusion and similarly positioned arterioles in unoperated 56-day-old NW rats.

\section{MATERIALS AND METHODS Surgery and Occlusion of MCA}

Ten 36-day-old NW rats including members of each sex were anesthetized with ketamine hydrochloride $(136-150 \mathrm{mg} / \mathrm{kg}$ body weight, IM). Details of the equipment and surgery necessary to expose, dissect, and li-

Received December 5, 1983; accepted March 30, 1984. 
gate the MCA are given elsewhere (Coyle, 1982). A $1-2 \mathrm{~mm}$ diameter $\left(0.785-3.142 \mathrm{~mm}^{2}\right.$ in area) craniectomy was made with a number 6 dental burr about $1 \mathrm{~mm}$ rostral to and 1-2 $\mathrm{mm}$ dorsal to the fusion point of the zygoma with the squamosal bone. Dura mater was carefully pierced with a number 11 scalpel blade and then dissected taking care to avoid branches of the middle meningeal artery. A monofilament nylon thread, about $35 \mu \mathrm{m}$ in diameter, was used for ligating the MCA. A square knot in the thread secured occlusion of the vessel dorsal to the rhinal fissure but ventral to MCA rami distributing to frontal, parietal, and occipital cortical regions.

\section{Vessel Preparations}

Rats were killed according to the following schedule after MCA occlusion: three on the second day, five on the 20th day, and two on the 26th day. Five unoperated 56-day animals were controls. Rats representing each sex were anesthetized with ether before surgical exposure of the left external jugular vein (Greene, 1935). Papaverine hydrochloride ( $40-50 \mathrm{mg} / \mathrm{kg}$ body weight) was injected intravenously. Skin and periosteum over the skull were reflected. Undiluted Vultex, a white latex-based compound was warmed to $38^{\circ} \mathrm{C}$ and injected via the ascending aorta to make the size and course of cerebral vessels visible. Based upon many previous trials using this injection media and others (Coyle, $1975,1976,1978$ ), with or without opening the right atrium, consistently better results were obtained if the atrium was left intact and the thoracic aorta was clamped at the diaphragm as done here.

\section{Visualization of Vessels}

Patterns of vessel filling with latex were observed through the skull thinned with a dental burr (Coyle and Jokelainen, 1982). Thirty to $\mathbf{4 5}$ minutes after latex injection, the dorsal aspect of the skull was removed, dura mater was carefully reflected, and decapitation was performed. Tissues were fixed for several weeks in $10 \%$ neutral buffered formalin before brain removal from the skull. All brains were placed in a standard dorsal orientation for photography.

Collateral vessels stem from branches of the anterior cerebral artery (ACA) and the MCA. Branch angles of two collaterals joined by an end-to-end anastomosis characteristi- cally face each other and allow identification of ACA and MCA branch origins (Figs. 1, 2).

\section{Measurements and Computations}

Coordinates $(\mathrm{x}, \mathrm{y})$ of about 70 points along the long axis of a collateral were sampled from a photograph with a Summagraphics Corporation Bit Pad interfaced (Coyle, 1981) to a Commodore Microcomputer. Vessel distance between adjacent sample points was computed as the hypotenuse of a right trian. gle, and vessel length was obtained by summing the segments. Vessel tortuosity (VT) was computed from vessel length (VL) divided by the straight line distance (SLD) between the two vessel ends (VT = VL/SLD). An anastomosis was the point of narrowest diameter of the vessel joining ACA and MCA branch points, or if a vessel narrowing was not evident, the anastomosis was defined as the point one half the vessel distance between ACA and MCA branch origins. The anastomosis diameter measured was the internal diameter of the collateral.

\section{Statistical Procedures}

The largest and next to largest diameter collateral were sampled for tortuosity measurements in each of three (frontal, parietal, occipital) regions of the two hemispheres of the five experimental rats with right MCA occlusion and five unoperated control rats. The six values were averaged to yield one tortuosity value for each hemisphere. Pairwise $t$ tests were used to compare right and left hemisphere anastomoses numbers and vessel tortuosity values. Two sample $t$ tests were used to compare anastomoses numbers and tortuosity values of experimental animals with those of the 56-day-old unoperated control group.

\section{Control of Potential Problem Areas MCA occlusion}

Because the MCA was not transected, control measures were used to insure the ligation occluded the vessel. High magnification observation of the MCA immediately distal to the ligature indicated a bloodless segment of the vessel after ligation (Fig. 2), providing evidence that flow via the MCA was interrupted. The MCA immediately distal to the ligation was equal to or smaller in diameter than the portion proximal to the ligation, giving no evidence of a poststenotic dilation that characteristically occurs in a stenotic 


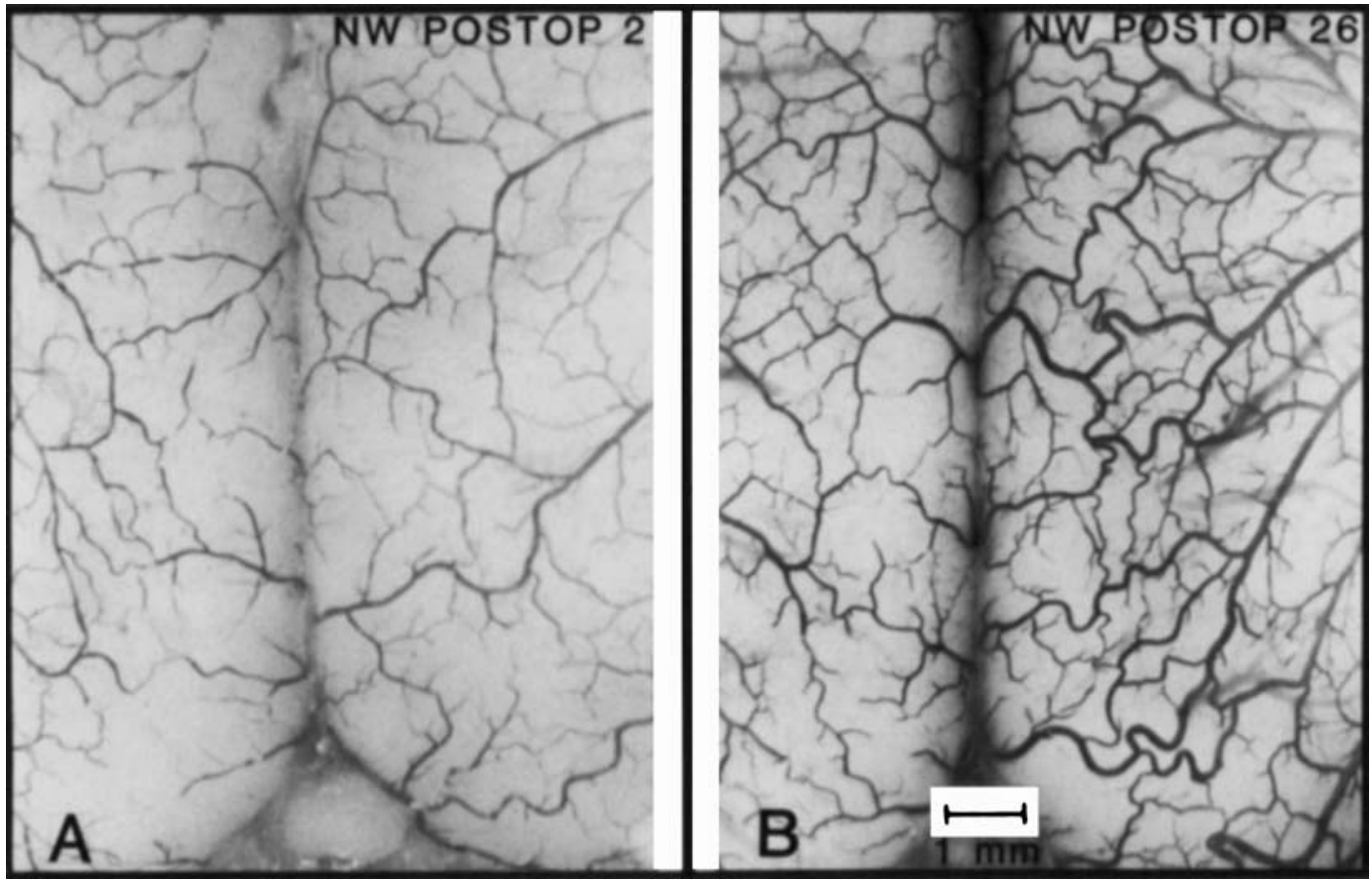

Fig. 1. A) Dorsal view of right and left hemisphere collaterals 2 days after right MCA occlusion. Note lack of evident vessel asymmetry between hemispheres. Blind ending of latex in vessels in lower left region indicates incomplete filling. B) Same view as in A but 26 days after the occlusion. Note hemispheric asymmetry of vessel patterns. No papaverine. NW, normal Wistar rat. vessel (Roach, 1980). Visual observation through the thinned skull of the pial surface during latex injection verified dorsal MCA pial surface vessels filled via collateral supply from the anterior cerebral artery, indicating resistance to flow across the anastomses was lower than the resistance drop across the ligated segment of the MCA. This is in contrast to the control rat without MCA ligation where the same pial surface vessels fill with latex via the MCA route (see Fig. 1 in Coyle and Jokelainen, 1982). All evidence indicates the MCA was occluded at the time the ligature was secured with a square knot and at latex injection time 20 days later.

\section{Unfilled vessels}

Rat pial surface arterioles do not criss-cross one another. An uninterrupted latex-filled arteriole is necessary to define its spatial course and to provide evidence that unfilled arterioles do not cross its path. Incomplete patterns are easily recognized by media ending abruptly in a vessel (Fig. 1A). Only specimens with uninterrupted patterns were statistically analyzed in this study.

\section{Variable vessel diameter}

A vessel fixed in some unknown state of contraction is not easily compared to another vessel that may be fixed in a different state of contraction. Papaverine was used to standardize all vessels to maximal dilation and to minimize cerebrovascular resistance for latex filling. Because of media viscosity and the absence of vascular tone, aortic pressures meaningful for supply of blood (Berne and Levy, 1977) may be particularly misleading if applied during injection of Vultex.

\section{Pattern asymmetry}

Asymmetry of right-left hemisphere vascular patterns observed 20 days after rapid MCA ligation could not be due to latex since 


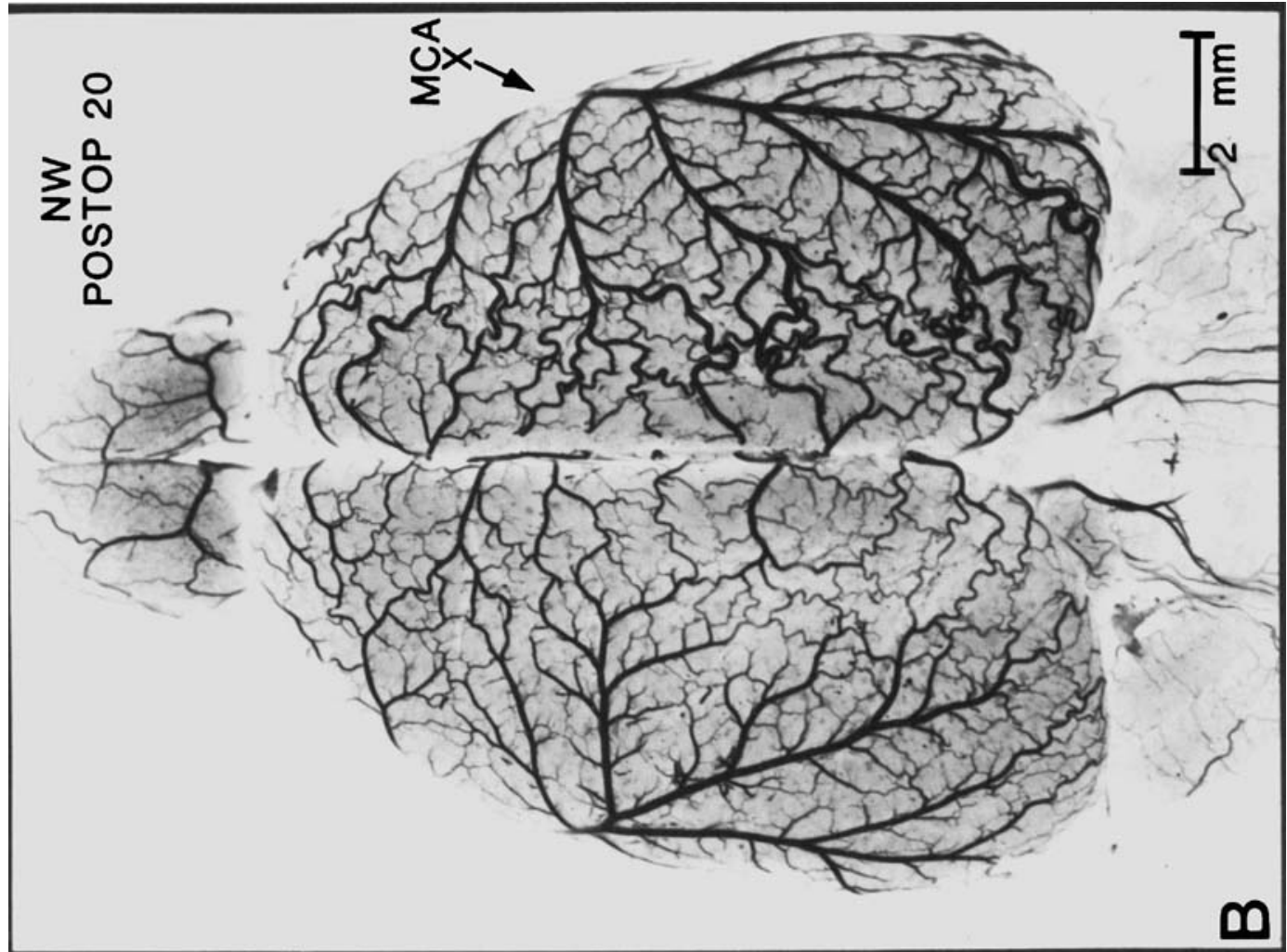

$$
\begin{aligned}
& \text { 产总 }
\end{aligned}
$$

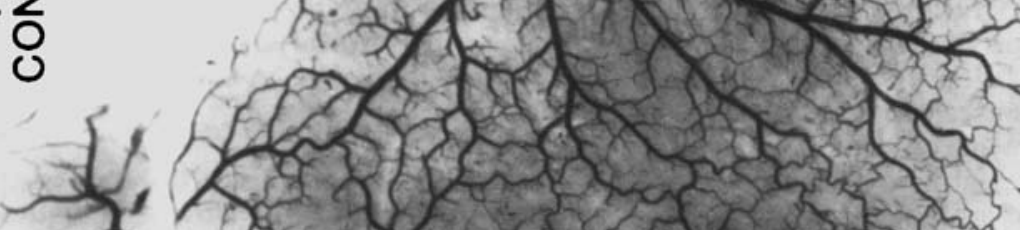$$
\text { 30 }
$$

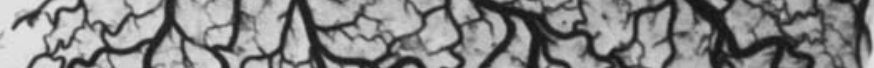

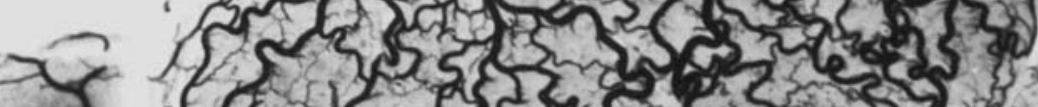

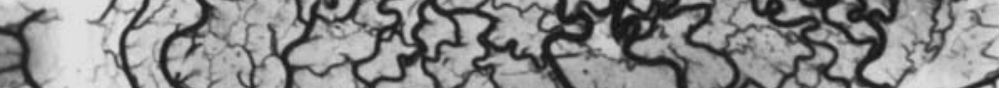

D

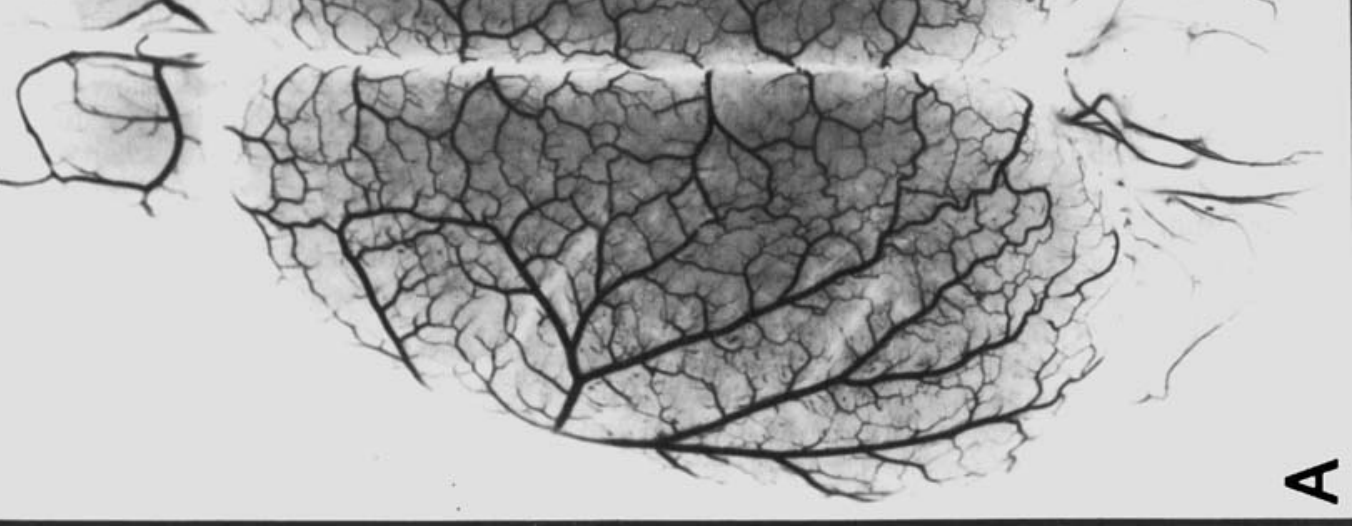


TABLE 1. Anastomoses data for five MCA-occluded and five unoperated control rats

\begin{tabular}{|c|c|c|c|c|c|c|}
\hline Class & $\begin{array}{c}\text { No. } \\
\text { anast } \\
\overrightarrow{\mathrm{X}} \pm \text { SEM } \\
\end{array}$ & $\begin{array}{l}\mathrm{t} \text { test } \\
\text { No. } \\
\text { anast } \\
\text { signif }\end{array}$ & $\begin{array}{c}0-59 \mu \mathrm{m} \\
\text { diameter } \\
\text { anast } \\
\overline{\mathrm{X}} \pm \mathrm{SEM}\end{array}$ & $\begin{array}{c}\mathrm{t} \text { test } \\
0-59 \mu \mathrm{m} \\
\text { signif }\end{array}$ & $\begin{array}{c}60-120 \mu \mathrm{m} \\
\text { diameter } \\
\text { anast } \\
\overline{\mathrm{X}} \pm \mathrm{SEM}\end{array}$ & $\begin{array}{c}t \text { test } \\
60-120 \\
\mu \mathrm{m} \\
\text { signif }\end{array}$ \\
\hline $\begin{array}{l}\text { MCA occl } \\
\text { Rt hem } \\
\text { Lt hem }\end{array}$ & $\begin{array}{l}26.6 \pm 2 \\
24.0 \pm 1\end{array}$ & 0.35 & $\begin{array}{l}16.4 \pm 2.4 \\
22.0 \pm 1.5\end{array}$ & 0.10 & $\begin{array}{r}10.2 \pm 1.2 \\
2.5 \pm 1.1\end{array}$ & 0.00 \\
\hline $\begin{array}{c}\text { Control ra } \\
\text { Rt hem } \\
\text { Lt hem }\end{array}$ & $\begin{array}{l}28.4 \pm 2 \\
30.8 \pm 2\end{array}$ & 0.09 & $\begin{array}{l}26.2 \pm 2.4 \\
28.8 \pm 2.1\end{array}$ & 0.10 & $\begin{array}{l}2.8 \pm 0.4 \\
2.5 \pm 0.3\end{array}$ & 0.81 \\
\hline $\begin{array}{c}\text { Hemisphe } \\
\text { Rt occl } \\
\text { Rt cont }\end{array}$ & $\begin{array}{l}26.6 \pm 2 \\
28.4 \pm 2\end{array}$ & 0.59 & $\begin{array}{l}16.4 \pm 2.4 \\
26.2 \pm 2.4\end{array}$ & 0.03 & $\begin{array}{r}10.2 \pm 1.2 \\
2.8 \pm 0.4 \\
\end{array}$ & 0.00 \\
\hline
\end{tabular}

the asymmetry was hardly evident 2 days after the occlusion (Fig. 1A). Nor was the asymmetry due to differential action of the papaverine because specimens prepared without it were asymmetric 26 days after the ligation (Fig. 1B) Thus, to demonstrate evident vascular change in the collaterals a time period greater than 2 days was necessary.

\section{RESULTS \\ Patterns of Asymmetry}

Vessel patterns are evident in Figure 2 for two 56-day-old NW rats. Figure 2A shows the pattern of a control rat. End-to-end anastomoses forming diamond shaped collateral units are present in frontal, parietal, and occipital regions. Vessels of the right hemisphere are of the same approximate diameter as vessels of the homologous area of the other hemisphere.

In the rat of Figure $2 \mathrm{~B}$ the right middle cerebral artery (MCA) was rapidly occluded at 36 days of age. A pattern of asymmetry exists between vessels of the two hemispheres (Fig. 2B) that differs from the unoperated 56-day-old NW control rat (Fig. 2A). There was hemispheric asymmetry in size (internal vessel diameter) and tortuosity values of the collaterals.

\section{Number and Size of Collaterals}

Twenty days after right MCA occlusion the average number of anastomoses on the oc-

Fig. 2. Dorsal view of cerebral arteries after papaverine and latex injections. A) Normal Wistar (NW) control rat, 56 days old; B) 56 -day-old NW rat 20 days after rapid occlusion of the right middle cerebral artery (MCA). Collateral pattern (vessel diameters and tortuosities) of right hemisphere differs from that of the left hemisphere and the control animal pattern. cluded side was not significantly different $(\mathrm{P}$ $>0.05$ ) from the average number of anastomoses on the left unoccluded side (Table 1). Nor was the average number of anastomoses on the right occluded side significantly different from the average number of anastomoses on the right hemisphere of unoperated agematched control rats.

In MCA occluded rats, there were significantly $(\mathrm{P}<0.001)$ more large $(60-120 \mu \mathrm{m})$ diameter anastomoses on the right hemisphere as compared to large diameter collaterals on the left side (Table 1). Similarly, there were more large diameter collaterals on the right hemisphere of the occluded rats as compared to large diameter vessels on the right hemisphere of the unoperated control animals. There were fewer small $(0-59 \mu \mathrm{m})$ diameter collaterals on the right MCA occluded side as compared to the left hemisphere or the right side of unoperated control rats (Table 1).

\section{Tortuosity of Collaterals}

Analysis of right versus left vessel tortuosity values in rats with MCA occlusion indicated significantly $(P<0.05)$ greater tortuosity values of large diameter collaterals on the right hemisphere (Fig. 3A). Average tortuosity values of vessels on the MCA occluded side were significantly $(\mathrm{P}<0.01)$ greater than mean tortuosity values for the right hemisphere of unoperated control rats of similar age (Fig. 3B). The increase in tortuosity indicates collaterals on the occluded side were $24 \%$ longer (tortuosity difference $x$ 100) than vessels on the left hemisphere or $29 \%$ longer than vessels on the right hemisphere of unoperated controls. There was no significant $(P>0.05)$ increase in the mean tortuosity value for the left hemisphere of occluded rats compared to unoperated ones. 


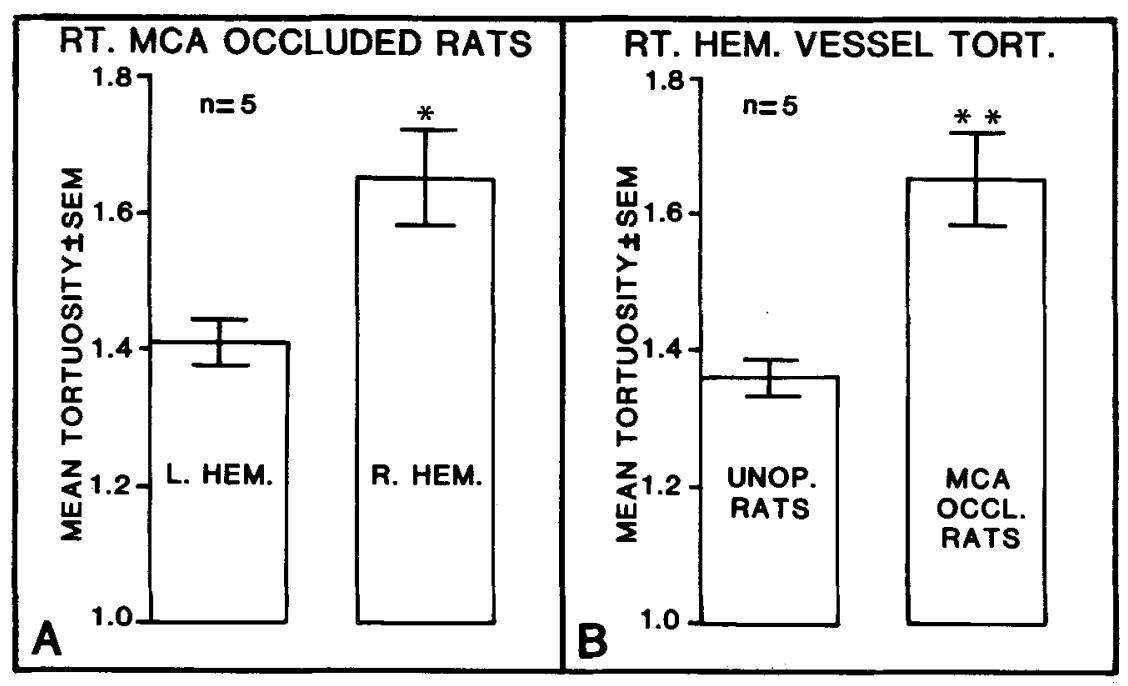

Fig. 3. A) Vessel tortuosity values for left (L) and right (R) hemispheres (HEM) of 56-day-old normal Wistar rats 20 days after occlusion of the right (RT) middle cerebral artery (MCA). $* \mathrm{P}<0.05$. B) Tortuosity (TORT) values

In unoperated 56-day-old control rats, there was no significant $(\mathrm{P}>0.05)$ difference of large vessel tortuosity values between hemispheres.

\section{DISCUSSION \\ Functional Considerations}

Anatomical anastomoses join distal rami of the three major cerebral arteries in 36-dayold normal Wistar rats (Coyle and Jokelainen, 1982). Since the parenchymal arteries in brain are end-arteries (Cobb, 1931), the pial surface junctions must provide adequate collateral supply to protect the tissue from infarction after rapid MCA occlusion in the normal Wistar (Coyle, 1982) and Wistar Kyoto rat (Coyle and Jokelainen, 1983). Had the collateral supply been inadequate as in the spontaneously hypertensive stroke-prone rat (Coyle and Jokelainen, 1983), an infarct would have occurred and cortical atrophy would have been grossly evident 20 days after MCA occlusion. Neither an infarct nor cortical atrophy was observed in the normal Wistar rats of this study.

\section{Numbers of Collaterals}

Because the formation of new collaterals requires time for cellular replication and vessel development (Schaper and Schaper, 1976; for the right hemisphere of 56-day-old unoperated (UNOP) rats and animals 20 days after MCA occlusion (OCCL). $* * P<0.01$.

Schaper and Wusten, 1979), immediate protection against infarction after MCA ligation came from the blood supply of vessels existing at the occlusion time. Because the number of anastomoses on the right was not significantly different from the number on the left side, there was no evidence either that new collaterals were added during the 20 day period or that vessels on the left unoccluded side were not filled with latex. Yet 20 days after the ligation, the collaterals were significantly different in size (internal diameter) and shape (tortuosity) from vessels of unoperated 56-day-old control rats. The size and shape differences are evidence of vascular change in the collaterals after MCA ligation.

\section{Large Diameter Collaterals 20 Days After MCA Occlusion}

There were significantly more large (60$120 \mu \mathrm{m})$ diameter collaterals on the right hemisphere than on the left hemisphere. The asymmetry may be due to an early passive enlargement of existing vessels where the collaterals "give" under increased tangential wall stress (Schaper, 1967) followed in time by structural change of the collateral vascular wall (Schaper and Pasyk, 1976; Schaper, 1979; Strandness, 1980; Odori et al., 
1983). Because the resistance to blood flow was inversely related to the 4th power of the radius of the vessel (Berne and Levy, 1977), resistance to collateral flow was lower in the larger diameter collaterals as compared to the smaller diameter ones. By increasing the number of large diameter collaterals in parallel arrangement, the resistance to collateral flow was reduced.

\section{Small Diameter Vessels}

Fewer small (0-59 $\mu \mathrm{m})$ diameter collaterals were present on the MCA occluded side as compared to unoperated control rats. Since the number of small diameter collaterals on the occluded side was significantly less than the number of small diameter collaterals in either 36- or 56-day-old unoperated rats (Coyle and Jokelainen, 1982), there is no evidence new collaterals were added. Still, the possibility exists that new vessels were being formed (Odori et al., 1983) or that small diameter ones were not filled with the latex. Whereas enlargement of small diameter vessels reduces resistance to collateral blood flow, added new small diameter collaterals would have less conductance (Berne and Levy, 1977). Apparently, collateral supply to the MCA tissue field in the young rat is mainly, if not totally, increased by enlargement of small diameter pial surface vessels existing at occlusion time.

\section{Tortuosity}

Collaterals on the side of the occlusion had greater tortuosity than control vessels joining ACA-MCA rami in unoperated 56-dayold rats. An increase in tortuosity may be apparent or real. If a collateral maintains constant length, atrophy of the underlying tissue could result in an apparent increase in tortuosity of a vessel by reducing the distance between ends of the vessel. There was no evident atrophy in any brain of this study.

A true increase in vessel tortuosity signifies a longer vessel. Collateral elongation by 24-29\% would seem not to be due to longitudinal dilatation or stretch alone, for the lumenal cross section area would have been reduced; in fact, diameters of anastomoses were increased. Mechanical, chemical, and neural factors may be involved in structural change of the collateral vascular wall (Strandness, 1980; Bevan et al., 1983). Although the occlusion most likely blocked neural activity of fibers on the MCA, a direct neural influence on the collaterals doesn't seem likely because nerve fibers were not observed on these collaterals in electron micrographs (Jokelainen et al., 1982). The increases in collateral length and diameter most likely involved either hypertrophy or hyperplasia or both, but the mechanisms and cellular alterations underlying these changes in the dorsal arterial collaterals remain to be elucidated.

\section{ACKNOWLEDGMENTS}

The author wishes to thank Tom Ten Have and Anthony Schork of the Biostatistics Department for helpful assistance with the statistical analysis. Support for this investigation was from NIH HLBI grant 18575.

\section{LITERATURE CTTED}

Berne, R.M., and M.N. Levy (1977) Cardiovascular Physiology. C.V. Mosby, St. Louis, pp. 59-64.

Bevan, R.D., H. Tsuru, and J.A. Bevan (1983) Cerebral artery mass in the rabbit is reduced by chronic sympathetic denervation. Stroke, 14:393-396.

Black, K.L., B.R. Culp, D. Madison, O.S. Randall, and W.E.M. Lands (1979) The protective effects of dietary fish oil on focal cerebral infarction. Prostagland. Med., 3:257-268.

Cobb, S. (1931) The question of end-arteries in the brain and the mechanism of infarction. Arch. Neurol. Psychiat, $25: 273-280$.

Coyle, P. (1975) Arterial patterns of the rat rhinencephalon and related structures. Exp. Neurol., 49:671690.

Coyle, P. (1976) Arterial and venous vessel patterns in rat septal structures. In: The Septal Nuclei. J.F. DeFrance, ed. Plenum Press, New York, pp. 133-146.

Coyle, P. (1978) Spatial features of the rat hippocampal vascular system. Exp. Neurol., 58:549-561.

Coyle, P. (1981) PET interface to Bit Pad. Micro-The 6502/6809 Journal, 38:83-85.

Coyle, P. (1982) Middle cerebral artery occlusion in the young rat. Stroke, 13:855 -859.

Coyle, P., and P.T. Jokelainen (1982) Dorsal cerebral arterial collaterals of the rat. Anat. Rec., 203:397-404,

Coyle, P., and P.T. Jokelainen (1983) Differential outcome to middle cerebral artery occlusion in spontaneously hypertensive stroke-prone rats (SHRSP) and Wistar Kyoto (WKY) rats. Stroke, 14:605-611.

Garcia, J.H., and Y. Kamijyo (1974) Cerebral infarction. Evolution of histopathological changes after occlusion of the middle cerebral artery in primates. J. Neuropathol. Exp. Neurol., 33:408-421.

Greene, E.C. (1935) Anatomy of the rat. Trans. Am. Phil. Soc. N.S., 27:1-370.

Hudgins, W.R., and J.H. Garcia (1970) Transorbital approach to the middle cerebral artery of the squirrel monkey: A technique for experimental cerebral infarction applicable to ultrastructural studies. Stroke, 1:107-111.

Jokelainen, P.T., G.I. Jokelainen, and P. Coyle (1982) Non-random distribution of rat pial arterial sphincters. In: Cerebral Blood Flow: Effects of Nerves and Neurotransmitters. DD. Heistad and M.L. Marcus, eds. Elsevier North.Holland, Inc., New York, pp. 107-116.

O'Brien, M.D., and A.G. Waltz (1973) Transorbital approach for occluding the middle cerebral artery with- 
out craniectomy. Stroke, 4:201-206.

Odori, T., A. Paskine-Hurlburt, and N.K. Hollenberg (1983) Increase in collateral arterial endothelial cell proliferation induced by captopril after renal artery stenosis in the rat. Hypertension, 5:307-311.

Roach, M.R. (1980) Remodeling of the arterial wall with poststenotic dilation. In: Vascular Neuroeffector Mech anisms. J.A. Bevan, T. Godfraind, R.A. Maxwell, and P.M. Vanhoutte, eds. Raven Press, New York, pp. 213218.

Schaper, W. (1967) Tangential wall stress as a molding force in the development of collateral vessels in the canine heart. Experientia, 23:595-599.

Schaper, W. (1979) Mechanisms of collateral enlargement. In: The Pathophysiology of Myocardial Perfusion. W. Schaper, ed. Elsevier North-Holland, New York, pp. 458-470.

Schaper, W., and S. Pasyk (1976) Influence of collateral flow on the ischemic tolerance of the heart following acute and subacute coronary occlusion. Circulation, 53(Suppl. 1):57-62.
Schaper, W., and J. Schaper (1976) Collateral circulation. In: Vascular Neuroeffector Mechanisms. 2nd Int Symp., Odense, 1975. J.A. Bevan, G. Burnstock, B. Johansson, R.A. Maxwell, and O.A. Nedergaard, eds. S. Karger, New York, pp. 28-34.

Schaper, W., and B. Wusten (1979) Collateral circulation. In: The Pathophysiology of Myocardial Perfusion. W. Schaper, ed. Elsevier North-Holland, New York, pp. 415-436.

Strandness, D.E. Jr. (1980) Biology of the collateral circulation. In: Structure and Function of the Circulation. C.J. Schwartz, N.T. Werthessen, and S. Wolf, eds. Plenum Press, New York, pp. 487-535.

Sundt, T.M. Jr., and A.G. Waltz (1966) Experimental cerebral infarction: Retroorbital, extradural approach for occluding the middle cerebral artery. Mayo Clin. Proc., 41:159-168.

Waltz, A.G., and T.M. Sundt (1967) The microvasculature and microcirculation of the cerebral cortex after arterial occlusion. Brain, 90:681-696. 